\title{
Making the best of Canada's worsening residency mismatch
}

\author{
n Cite as: CMAJ 2018 May 14;190:E603-4. doi: 10.1503/cmaj.109-5598
}

Posted on cmajnews.com on Apr. 25, 2018.

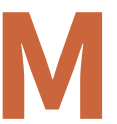
ore Canadian medical graduates than ever were unable to secure residency placements in this year's match. However, new supports will hopefully ensure they are no longer left to fend for themselves while their medical careers are on hold.

One hundred and fifteen of this year's graduates didn't match to residency placements, up from 99 last year and 77 the year before. There were also 54 graduates from previous years who went unmatched again, up from 46 last year.

"There's a snowball effect," said Dr. Geneviève Moineau, president and CEO of the Association of Faculties of Medicine of
Canada. "Every year you have more people going unmatched, and more will be applying the next year and adding to the pressure."

Canadian medical schools now have some supports for unmatched graduates. "They all look quite robust," said Kaylynn Purdy, vice-president of education for the Canadian Federation of Medical Students (CFMS). In addition to providing career counselling, some schools allow students to stay for a fifth year at reduced tuition, or offer one-year graduate programs to provide extra clinical and research experience.

The CFMS recently launched a mentorship network to connect graduates with

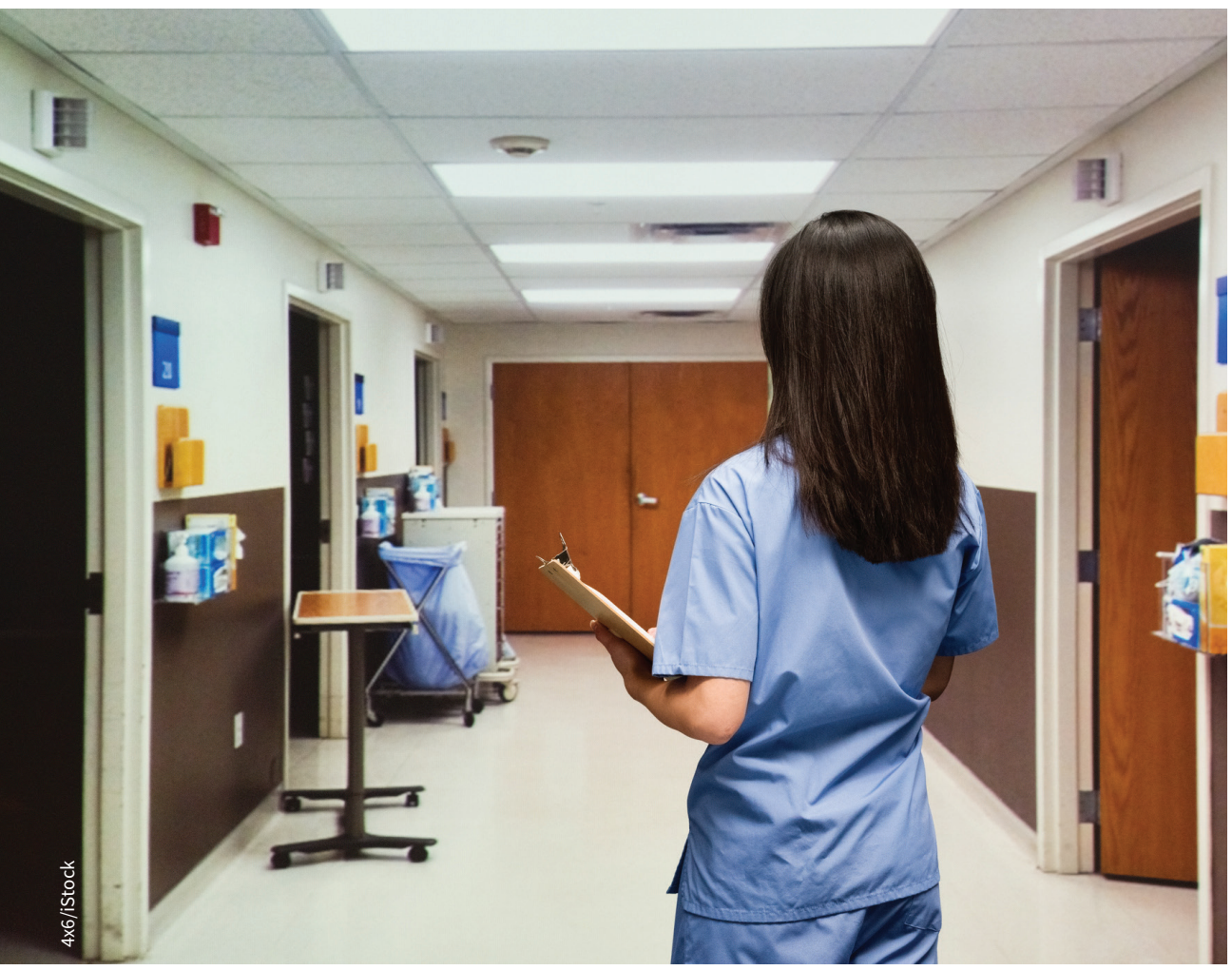

Medical schools and trainees are ramping up supports for the growing number of Canadian medical graduates shut out of residency.

others who went unmatched in the past but still had fulfilling careers. "We heard from unmatched students that they didn't have anywhere to turn for advice," Purdy said. "Student affairs offices and deans and faculty members don't necessarily understand the decisions or feelings around going unmatched."

The network connects graduates with mentors in the same specialty and province. Many of the mentors signed up because it is something they wished they had access to when they went unmatched, Purdy said. "Before, students kind of found each other by happenstance or through friends," but more often, going unmatched meant going it alone.

"There's a huge stigma," Purdy explained. "A lot of people still assume unmatched students must be at the bottom of the class, and that's definitely not what we're seeing." The majority of Canadian graduates who don't match to a residency placement are excellent students, she said. "It's the system that made them not match."

A decade ago, there were 111 residency placements per 100 Canadian medical graduates, ensuring some flexibility in the match. But recent cuts to residency positions have reduced that ratio to 101 seats per 100 graduates. An ongoing exodus of medical graduates from Quebec has also increased competition for positions elsewhere in Canada. This year, 69 of 78 residency spots that went unfilled were in Quebec.

The match is further complicated because spots initially earmarked for Canadian graduates are open to international graduates in the second round. In the last five years, $30 \%-50 \%$ of those spots were filled by international medical 
graduates, said Moineau. Keeping those applicant streams separate is one way governments could fix the match "without having to spend more money."

Without government action to protect or increase the number of residency positions, there simply won't be enough spots for every qualified Canadian graduate, said
Moineau. "These are the best and brightest, they got into medical school in Canada, and to have a system where they are basically told there is no room for you is just devastating."

Ontario recently announced it would open 53 additional positions for unmatched graduates in the province so long as they commit to work for two years in an underserved area after residency. "This is a good immediate step," said Moineau, but it won't address the overall imbalance in the match. "Now we have to be having the conversation about 2019."

Lauren Vogel, CMAJ 